\title{
Induced Resistance to Ustilago maydis in Zea mays Inoculated in Non-Sterile Conditions
}

\author{
Domingo Martínez-Soto and José Ruiz-Herrera*
}

\author{
Departamento de Ingeniería Genética, Unidad Irapuato, Centro de Investigación y de Estudios Avanzados \\ del Instituto Politécnico Nacional, Irapuato, Gto., México
}

\begin{abstract}
Plants are able to acquire induced resistance to pathogens (priming) by its previous exposure to biotic or abiotic stresses. To analyze whether this process is involved in the maize infection by Ustilago maydis, we have compared the infection occurring in plants inoculated under axenic conditions or in sterile soil to plants grown in nonsterile soil. Our results showed that plants grown under axenic conditions were more susceptible to infection than those inoculated in non-sterile soil. Accordingly, disease symptoms: chlorosis development, anthocyanin production, tumor development, and necrosis, were more and severe in axenic plants. In addition, cell death and reactive oxygen species production, as well as ethylene, were higher in axenic plants. These observations indicate for the first time, that different physical stressors and contact with microorganisms of the environment are responsible for the induction of resistance (priming) in this pathosystem.
\end{abstract}

Keywords: Ustilago maydis, Zea mays, Biotic and abiotic stresses, induced resistance, Priming effect.

\section{INTRODUCTION}

Infection processes in plant have been metaphorically compared with warfare, where the attack and defense strategies are the molecular mechanisms developed and used by the interacting participants. The defense used by both contenders in the pathogenic processes are the metabolites and proteins synthesized by each organism for attack or defense [1]. The plant defense system starts with its physical barriers such as the cuticle and cell wall, which when damaged by pathogens, serve as a source of signaling for the activation of resistance molecular mechanisms and systemic signals [2], causing in the plant a transcriptional and metabolic reprogramming [3]. This defense mechanism resembles the animals innate immunity system [4]. In the early literature the term used to designate the systemic immunity mechanisms involved in plant defense was denominated "sensitization" [5]. At the present time, this phenomenon is known as priming or induced resistance mechanism, which is defined as the physiological state that allows the plants to respond to low stimuli levels quickly and strongly after having been exposed previously to a biotic or abiotic stress, among them: the attack of pathogens, exposure to different microorganism, even beneficial ones such as rhizobacteria, volatile organic compounds (VOCs), osmotic stress, temperature stress, mechanical damage, and synthetic compounds [6-8]. This

*Address correspondence to this author at the Departamento de Ingeniería Genética, Unidad Irapuato, Centro de Investigación y de Estudios Avanzados del Instituto Politécnico Nacional, Irapuato, Gto., México;

Tel: +52 (462) 62396 00; Fax: +52 (462) 62458 46;

E-mail: jruiz@ira.cinvestav.mx response includes activation of genes encoding resistance proteins, cell death, production of reactive oxygen species (ROS), and phytohormones, although the molecular mechanism is not are well known $[6,8,9]$. Most studies on the induced resistance phenomenon have been conducted using dicotyledonous plants, but more recently it was demonstrated that exposure of maize plants to Pseudomonas putida induced resistance to Colletotrichum graminicola infection [10].

Ustilago maydis is a Basidiomycota pathogen of maize (Zea mays), causative agent of the maize disease known as common smut, which causes loss of about $2 \%$ of all maize produced in the world (approximately 787 million T) each year [11,12]. In México, this maize disease caused by $U$. maydis is known as Huitlacoche, and since prehispanic times it is used as food with high economic and nutritional values, including its good taste [12].

$U$. maydis has a complex life cycle involving a saprophytic yeast-like haploid stage (sporidia), and a mycelial heterokaryotic virulent form originated by the mating of sexually compatible sporidia. The characteristic symptoms of the disease are development of chlorosis, increased production of anthocyanins, and especially formation of tumors or galls in all the aerial parts of the plant [12-14]. Previously it has been demonstrated that under axenic conditions $U$. maydis has the capacity to infect nonnatural hosts [15-19]. Taking into consideration these results, and the above mentioned observation that maize has the capacity to acquire induced resistance by exposure to a bacterium [10], we decided to analyze whether a similar phenomenon occurred during 
infection of maize by $U$. maydis. To this aim, we compared the severity of infection of maize plants infected by this fungus under axenic or sterile soil conditions, to those infected in non-sterile soil.

\section{MATERIALS AND METHODS}

\section{Strains of the Fungus and Plants}

The haploid, wild type, and sexually compatible strains of $U$. maydis FB1 $\left(a_{1} b_{1}\right)$ and FB2 $\left(a_{2} b_{2}\right)$ [20] were used in this study. Zea mays (cv Cacahuazintle), a Mexican native maize cultivar, that we have used in all our previous studies because its high susceptibility to U. maydis (e.g. Martínez-Espinoza et al. [21]; RuizHerrera et al. [22]), was used as the host for $U$. maydis infection.

\section{Conditions and Medium for Fungus Growth}

$U$. maydis was grown in the complete medium (CM; Holliday [23]) of the following composition: glucose, $1 \%$; casein hydrolyzate, $0.25 \%$; yeast extract, $0.1 \%$; $\mathrm{NH}_{4} \mathrm{NO}_{3}, 0.15 \% ; 62.5 \mathrm{ml}$ de salts solution per liter. The composition of the salts solution is the following: $\mathrm{KH}_{2} \mathrm{PO}_{4}, 16 \mathrm{~g} ; \mathrm{Na}_{2} \mathrm{SO}_{4}, 4 \mathrm{~g} ; \mathrm{KCl}, 8 \mathrm{~g} ; \mathrm{MgSO}_{4}, 2 \mathrm{~g}$; $\mathrm{CaCl}_{2}, 1 \mathrm{~g} ; \mathrm{H}_{3} \mathrm{BO}_{3}, 0.06 \mathrm{~g} ; \mathrm{MnCl}_{2} .4 \mathrm{H}_{2} \mathrm{O}, 0.14 \mathrm{~g} ; \mathrm{ZnCl}_{2}$, $0.4 \mathrm{~g} ; \mathrm{NaMoO}_{4} . \mathrm{H}_{2} \mathrm{O}, 0.04 \mathrm{~g} ; \mathrm{FeCl}_{3} .6 \mathrm{H}_{2} \mathrm{O}, 0.1 \mathrm{~g}$; $\mathrm{CuSO}_{4} .5 \mathrm{H}_{2} \mathrm{O}, 0.4 \mathrm{~g}$; sterile distilled water (SDW), to 1 liter. U. maydis strains were maintained in $50 \%$ glycerol at $-70{ }^{\circ} \mathrm{C}$, and recovered in liquid $\mathrm{CM}$, with shaking (200 rpm) at $28{ }^{\circ} \mathrm{C}$ for $20 \mathrm{~h}$. For inocula preparation the cells (sporidia) were recovered by centrifugation at $2500 \times g$ for $10 \mathrm{~min}$, washed three times with SDW, recovered by centrifugation, and suspended in $5 \mathrm{ml}$ of SDW. A mixture of equal cell numbers (sporidia) of the sexually compatible FB1 and FB2 strains was prepared $\left[10^{7}\right.$ cells (sporidia) $/ \mathrm{mL}$ counted with a Neubauer chamber 3900 (Hausser Scientific, Horsham PA, US)].

\section{Plant Growth and Inoculation Conditions}

MS (Murashige \& Skoog) synthetic medium (with the following solutions: Solution l: $\mathrm{NH}_{4} \mathrm{NO}_{3}, 20 \mathrm{mM}$; $\mathrm{KNO}_{3}, 18.8 \mathrm{mM} ; \mathrm{CaCl}_{2} . \mathrm{H}_{2} \mathrm{O}, 3 \mathrm{mM} ; \mathrm{MgSO}_{4} .7 \mathrm{H}_{2} \mathrm{O}, 1.5$ $\mathrm{mM}$; KI, $5 \mu \mathrm{M} ; \mathrm{H}_{3} \mathrm{BO}_{3}, 25 \mu \mathrm{M} ; \mathrm{MnSO}_{4} \cdot \mathrm{H}_{2} \mathrm{O}, 0.1 \mathrm{mM}$; $\mathrm{ZnSO}_{4} .7 \mathrm{H}_{2} \mathrm{O}, 30 \mathrm{mM} ; \mathrm{Na}_{2} \mathrm{MoO}_{4} .2 \mathrm{H}_{2} \mathrm{O}, 0.25 \mathrm{mg} / \mathrm{L}$; $\mathrm{CuSO}_{4} .5 \mathrm{H}_{2} \mathrm{O} 0.025 \mathrm{mg} / \mathrm{L} ; \mathrm{CoCl}_{2} .6 \mathrm{H}_{2} \mathrm{O}, 0.025 \mathrm{mg} / \mathrm{L}$. Solution II: $\mathrm{KH}_{2} \mathrm{PO}_{4}, 1.15 \mathrm{mM}$. Solution III: inositol, 100 $\mathrm{mg} / \mathrm{L} ; \mathrm{FeSO}_{4} .7 \mathrm{H}_{2} \mathrm{O}, 0.1 \mathrm{mM} ; \mathrm{Na}_{2}$ EDTA. $2 \mathrm{H}_{2} \mathrm{O}, 0.1 \mathrm{mM}$; glycine, $2 \mathrm{mg} / \mathrm{mL}$; pyridoxine- $\mathrm{HCl}, 0.5 \mathrm{mg} / \mathrm{L}$;; nicotinic acid, $0.5 \mathrm{mg} / \mathrm{mL}$; thiamine $-\mathrm{HCl}, 0.1 \mathrm{mg} / \mathrm{mL}$ ) [24] was used for growth of $Z$. mays plantlets under axenic conditions. Z. mays seeds were sterilized by immersion in $70 \%$ ethanol for $5 \mathrm{~min}$, followed by $20 \%$ sodium hypochlorite for 20 min with vigorous movements, and five washes with SDW. After this treatment, Z. mays seeds were placed under chlorine gases as described by Martínez-Soto et al. [17], and were germinated over a sterile wet bed of cotton within sterile glass containers. Finally, plantlets at 2 days post-germination (dpg) were infected by injection with syringe and needle of $100 \mu \mathrm{L}$ of the $U$. maydis cell suspension described above, and transferred to solid MS medium within Magenta vessels (Sigma-Aldrich V8505, St. Louis MO, US). Incubation proceeded at $25{ }^{\circ} \mathrm{C}$ with a photoperiod of $12 \mathrm{~h}$. When non-sterile soil was used, $Z$. mays plants were placed in plant pots containing a soil mixture $(1.5 \mathrm{~kg}$ sunshine mix (containing Dolomitic limestone to adjust media $\mathrm{pH}$ to $5.0-7.0$ and to provide calcium and magnesium. Gypsum is added as a source of sulfur and calcium), $3.5 \mathrm{~kg}$ forest soil, $200 \mathrm{~g}$ rich river soil, $150 \mathrm{~g}$ vermiculite, and $150 \mathrm{~g}$ perlite), and inoculated as described above. Finally, to determine whether soil microorganisms were involved in induced resistance, in some additional experiments maize plants were sowed in sterile soil kept in Magenta containers, and inoculated and grown as described above. For this purpose, the soil mixture already described was previously sterilized in the autoclave at $121^{\circ} \mathrm{C}$ for $20 \mathrm{~min}$ in two successive days, and with dry heat at $170{ }^{\circ} \mathrm{C}$ for $12 \mathrm{~h}$ in three successive days. In all conditions, control plantlets received SDW only.

All the chemicals used describe above were obtained from Sigma-Aldrich, San Louis MO, US).

\section{Determination of Damage and Symptoms in Infected Maize Plants}

Damage and symptoms of infection in plants were observed with a stereoscope (Leica MZ-8, Illinois, US) and photographed with a Spot digital camera (Diagnostic instruments, Houston TX, US). Photographs of whole plants were taken with a DMCFX12 camera (Panasonic, Osaka, JP). Symptoms and damage in infected plants were compared between the two evaluated conditions (priming, and no priming induction). The biomass of the infected and control plants was determined at different periods postinoculation by measurement of their dry weight.

\section{Observation of $U$. maydis Growth in Infected Plants}

Tissue sections of infected plants were obtained with a scalpel, and observed directly or after bleaching with boiling $70 \%$ ethanol for $5 \mathrm{~min}$ to remove chlorophyll. Observation was made by light microscopy 
with a Leica DMRE instrument, directly, or after staining with cotton blue-lactophenol (Sigma-Aldrich 61335 , St. Louis MO, US), and photographed with the Spot camera.

\section{Determination of Reactive Oxygen Species (ROS) Production}

ROS production was measured by the method of Sato et al. [25] with some modifications. Tissue sections were stained with 1,2,3-dihydrorhodamine [1,2,3-DHR; Sigma-Aldrich D1054, St. Louis MO, US) $(2.5 \mathrm{mg} / \mathrm{mL}$ in ethanol)] in darkness for $5 \mathrm{~min}$. The sections were observed with the Leica DMRE epifluorescence microscope (Wetzlar, DE) and photographed as described above. Areas with ROS production showed bright yellow fluorescence.

\section{Determination of Cell Death in Plant Tissues}

The method described by Martinez-Pacheco and Ruiz-Herrera [26] was used. Sections of infected tissue were placed on a slide, and $15 \mu \mathrm{L}$ of berberine sulfate [Sigma-Aldrich S579483 $(0.01 \mathrm{mg} / \mathrm{mL})$ St. Louis MO, US] were added. After $5 \mathrm{~min}$ in darkness the sections were observed in the Leica DMRE microscope by epifluorescence, and photographed as described above. Bright yellow fluorescence within the cells indicated the occurrence of cell death. To determine cell death at sites of infection or fungal growth through the plant tissues, sections were embedded in a solution of $0.01 \mathrm{~g} / \mathrm{mL}$ of trypan blue (Sigma-Aldrich T8154, St. Louis MO, US) in glycerol (Sigma-Aldrich G5516, St. Louis MO, US)/lactic acid (Sigma-Aldrich W261106, St. Louis MO, US)/water 1:1:1 v/v diluted with ethanol $(96 \%)(1: 2 \mathrm{v} / \mathrm{v})$ for $24 \mathrm{~h}$, washed with ethanol (96\%), and observed in the light microscope [27], and photographed as described above. The presence of dark blue aggregates in the plant tissues was indicative of cell death areas.

\section{Determination of Ethylene (ET)}

To measure ethylene production, at 10 days post inoculation (dpi), maize plantlets grown in soil were transferred to a similar system used for axenic growth (see Materials and methods). In both cases (soil and axenic), a rubber stopper was adapted to an upper culture Magenta vessel. Previous to ethylene measurement, the cover of magentas was removed for $30 \mathrm{~min}$ in order to homogenize the conditions for all plants. At the end of this period, magentas were covered again, and incubated under illuminated conditions for $3 \mathrm{~h}$ at $25{ }^{\circ} \mathrm{C}$, and $10 \mathrm{~mL}$ of gas were retrieved with a sterile syringe and needle and transferred to sterile Vacutainer tubes (Franklin Lakes NJ, US). Finally, samples were injected into a gas chromatograph (Hewlett 5890 Packard Series II; Ramsey MN, US), with a PLOT $Q$ column [Agilent Technologies, Santa Clara CA, US; HP- (30 m X 0.530 $\mathrm{mm} X 40 \mu \mathrm{m})]$. Ethylene concentration was calculated using known amounts of the gas as controls. The experiments were performed in triplicate and repeated independently three times, and Two ways ANOVA, Tukey-HSD analysis was applied.

\section{Determination of Salicylic Acid (SA)}

We used the method proposed by Malamy et al. [28]. Samples of $250 \mathrm{mg}$ of wet plant tissue were obtained at $10 \mathrm{dpi}$, and macerated in the presence of liquid $\mathrm{N}_{2}$. After this, $0.75 \mathrm{~mL}$ of $90 \%$ methanol and $5 \mu \mathrm{L}$ of a solution containing $0.1 \mu \mathrm{g} / \mu \mathrm{L}$ of ortho-anisic acid (ortho-methoxybenzoic acid) (Sigma-Aldrich W394300, St. Louis MO, US), as internal standard were added. The samples were incubated for $24 \mathrm{~h}$ at $4^{\circ} \mathrm{C}$, centrifuged at $13,000 \times g$ for $15 \mathrm{~min}$, the supernatant was recovered, and $0.75 \mathrm{~mL}$ of methanol were added to the pellet, and centrifuged again as described above. The two supernatants were mixed, methanol was evaporated with a stream of $\mathrm{N}_{2}$, the pellet was suspended in $0.5 \mathrm{~mL}$ of $5 \%$ trichloroacetic acid (TCA) (Sigma-Aldrich, T6399 St. Louis MO, US), the sample was centrifuged at $6000 \times g$ for $10 \mathrm{~min}$, the supernatant was recovered, and two volumes of a mixture $(1: 1)$ of ethyl acetate and cyclopentane were added. The samples were then incubated at room temperature for $10 \mathrm{~min}$, the organic phase was recovered and dried with $\mathrm{N}_{2}$ gas as described above. For derivatization, 20 $\mu \mathrm{L}$ of pyridine and $80 \mu \mathrm{L}$ of MSTFA [N-Methyl-N(trimethylsilyl) trifluoroacetamide (Sigma-Aldrich, 394866 St. Louis MO, US)] were added. The samples were incubated at $80^{\circ} \mathrm{C}$ for $1 \mathrm{~h}$, and finally the samples, as well as the samples of a standard curve were injected into a gas chromatograph (Agilent Technologies 7890A GC System, Palo Alto CA, US) with a column DB-1 MS IU [Agilent Technologies, Santa Clara CA, US; $(60 \mathrm{~m} \times 60.26 \times 60.5 \mu \mathrm{m})$ coupled to a MSD 5973 detector]. The experiments were performed in triplicate and repeated independently three times, and Two ways ANOVA, Tukey-HSD analysis was applied.

\section{RESULTS}

\section{Growth of Infected Maize Plants}

Infection with $U$. maydis reduced plant growth independently on the different conditions used. Thus, 


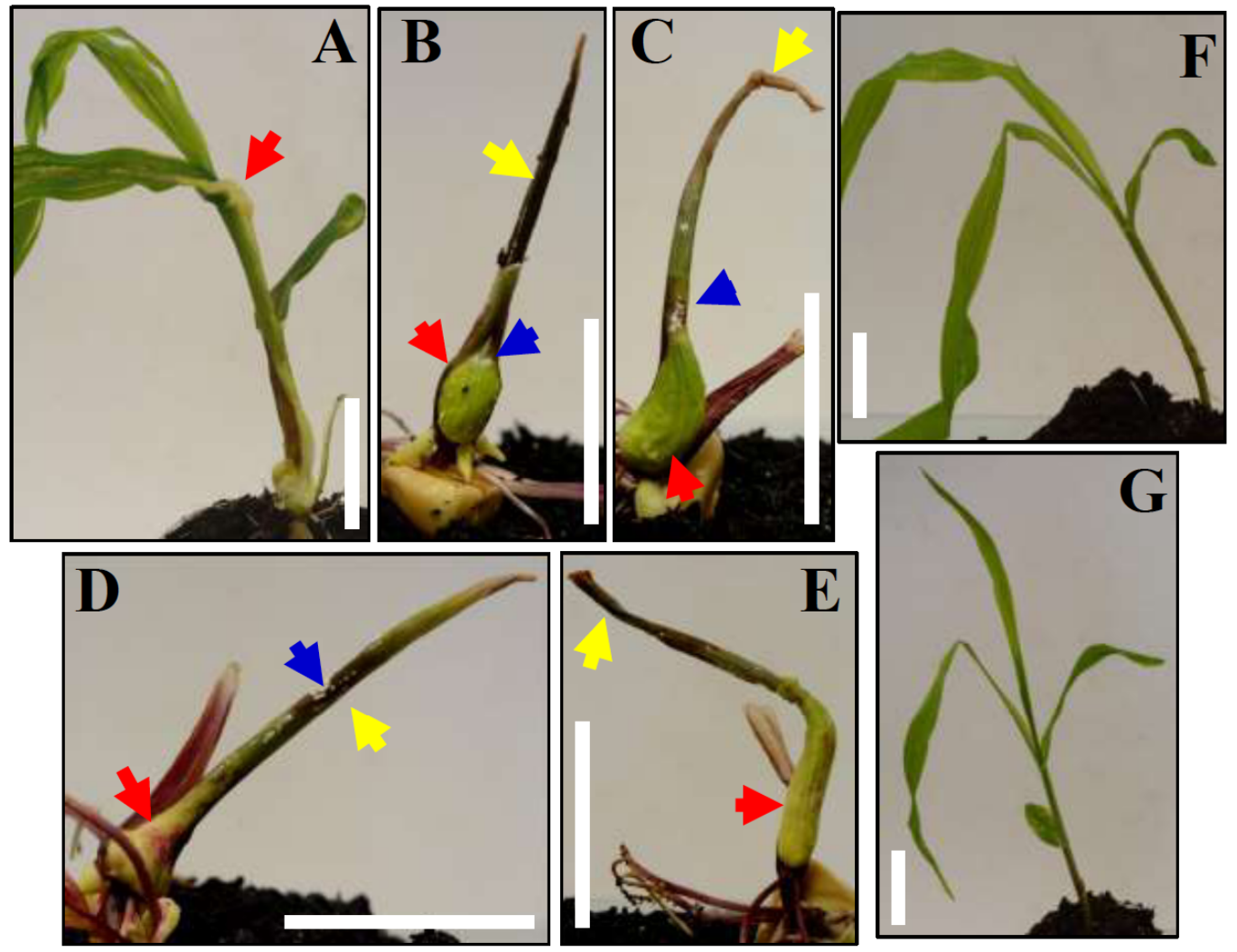

Figure 1: Representative photographs of maize plants infected in soil with $U$. maydis observed at $15 \mathrm{dpi}$. A, plant infected in non-sterile soil. $\mathbf{B}$ to $\mathbf{E}$, plants infected in sterile soil. $\mathbf{F}$ and $\mathbf{G}$, control plant grown in non-sterile or sterile respectively that received SDW only. Notice in $\mathbf{B}$ to $\mathbf{E}$, the larger tumors practically in all the plant, compared to the small tumor in Figure $\mathbf{A}$ (red arrows), important areas with necrosis (yellow arrows), mycelial growth of the fungus (blue arrows) in Figures B-E. Scale bar 3 $\mathrm{cm}$.

reduction in the size of plants infected in sterile soil at $15 \mathrm{dpi}$ was $43.7 \%$, and for plants infected in non-sterile soil was $29.1 \%$ (see Figure 1). At $15 \mathrm{dpi}$, the infected plants under axenic or soil conditions, had only $28.2 \%$ and $41.7 \%$ of biomass compared to that of the noninfected plants, respectively. These values corresponded to three different experiments using 10 plants in duplicates [a t-test student analysis was applied, and the difference between plants inoculated under axenic conditions or in soil was significant $(p<0.01)]$.

\section{Disease Symptoms in Infected Maize Plants}

All maize plants infected under either axenic or soil conditions showed the characteristic symptoms of the maize smut disease, such as chlorosis, increased synthesis of anthocyanins, general wilting, and tumor development with the presence of teliospores. Interestingly, the plants infected under axenic or sterile soil conditions showed more severe symptoms than those inoculated in non-sterile soil. For example, the plants infected under axenic conditions, and in sterile soil, developed larger tumors in all their tissues, and showed larger areas of necrosis, whereas in plants inoculated in non-sterile soil tumors were much smaller (compare Figure 1A to Figures 1B-1E, and Figure 2D to Figure 2A). Plants inoculated in sterile soil, but no those inoculated in non-sterile soil, also developed zones of necrosis and revealed superficial growth of fungal mycelium (Figures 1B-1D, yellow and blue arrows, respectively). In addition, in axenic plants, formation of teliospores started at earlier times of the infective process $(10 \mathrm{dpi})$, and at $15 \mathrm{dpi}$ teliospores were well formed, contrasting with plants infected in non-sterile soil in which teliospores formation initiated only after $15 \mathrm{dpi}$ (Figures 2B and 2E respectively). As expected, plants that received sterile distilled water (SDW) only, appeared healthy during all the observation period (Figures $1 \mathrm{~F}$ and 1G; and $\mathbf{2 C}$ and 2F). The quantitative analysis of the disease symptoms in plants infected by $U$. maydis under axenic or in nonsterile soil conditions is shown in Figures $\mathbf{3 A}$ and $\mathbf{3 B}$. These data confirmed that more and severe symptoms occurred in the plants infected under axenic conditions.

Larger areas of the infected tissue showing ROS production were observed in maize plants infected 

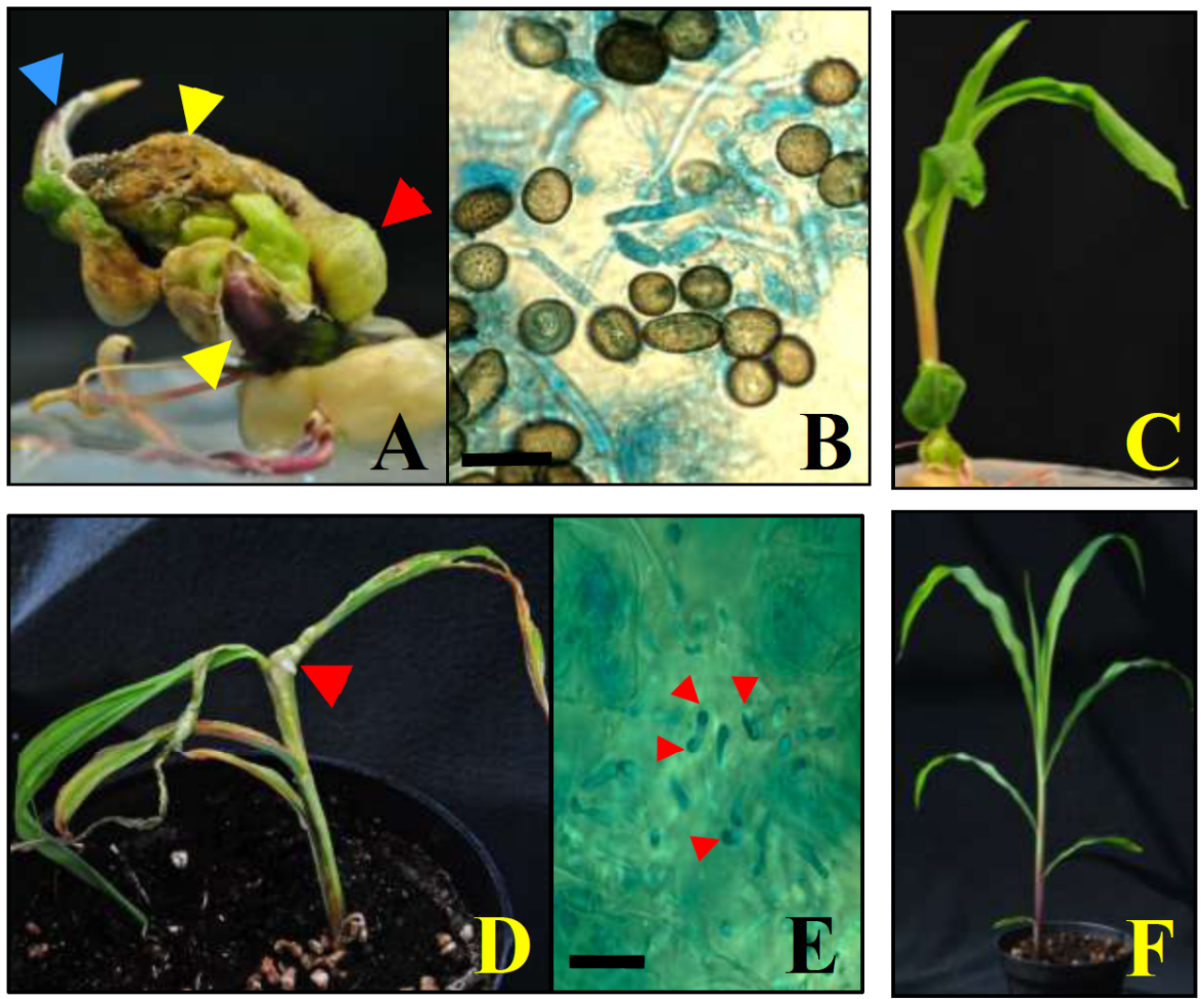

Figure 2: Representative photographs of whole and sections of maize plants infected with $U$. maydis at 15 dpi. A and B, plants infected under axenic conditions. D and $\mathbf{E}$, plants inoculated in non-sterile soil. $\mathbf{C}$ and $\mathbf{F}$, control plants that received SDW only under axenic or non-sterile soil conditions respectively. Notice in A severe damage of infection, development of large tumors in all the plant tissues (red arrow), mycelial growth of the fungus (blue arrow), and important areas of necrosis and anthocyanin production (yellow arrows). Notice in $\mathbf{B}$ mature teliospores formed under axenic conditions, and in $\mathbf{E}$ the initial stage in the formation of teliospores under non-sterile soil conditions at the same time as above (red arrows). Control plants showed no symptoms of infection ( $\mathbf{C}$ and $\mathbf{F}$ ). Scale bars in $\mathbf{B}$ and $\mathbf{E}, 50 \mu \mathrm{m}$.

A

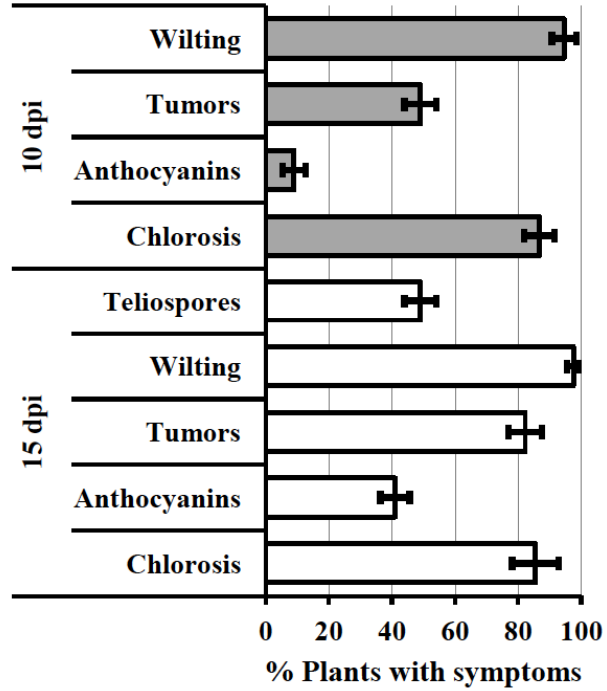

B

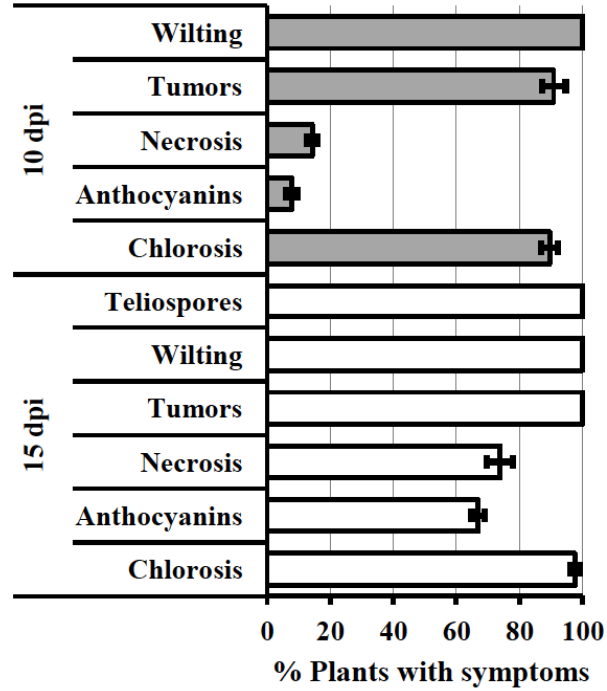

Figure 3: Quantitative data of the disease symptoms in maize plants infected by $U$. maydis. A, plants infected under non-sterile soil conditions. B, plants infected under axenic conditions. Gray bars represent plants at 10 days post inoculation (dpi), white bars represent plants at $15 \mathrm{dpi}$. Lines on each bar represent standard error values. Some symptoms were not observed in plants grown in soil, and accordingly are not included in the graphics. Data are averages of ten independent plants from three different experiments (30 plants in total). 

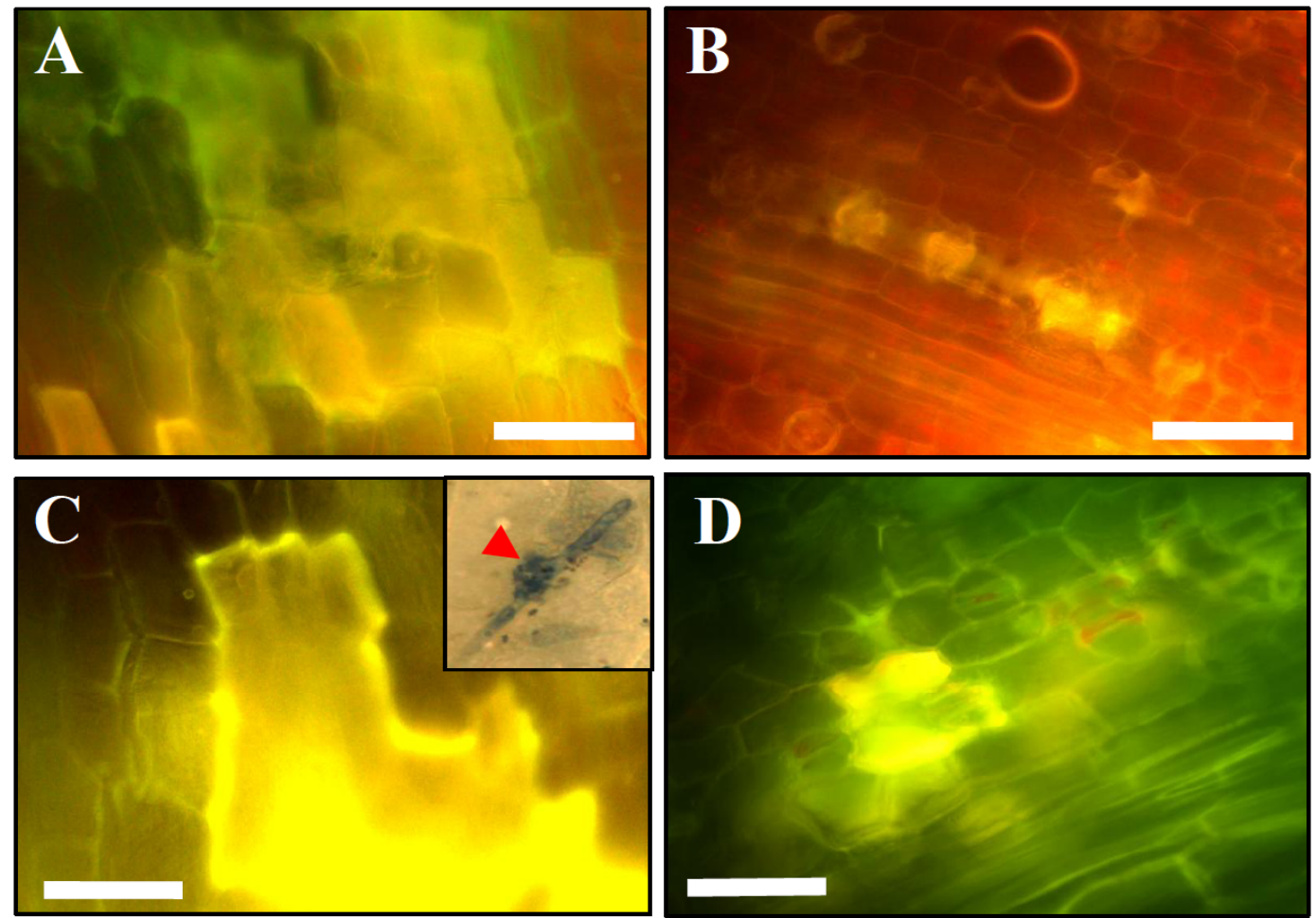

Figure 4: Representative photographs of plant sections showing the production of ROS or Cell death in maize plants infected by $U$. maydis. A and $\mathbf{C}$, sections of a plant infected by $U$. maydis under axenic conditions. $\mathbf{B}$ and $\mathbf{D}$, section of a plant inoculated in non-sterile soil. Notice in inset of $\mathbf{C}$ the presence of dark blue aggregates in the cells of the host plant suffering cell death due to the invasion of the fungus (red arrow). The presence of areas with yellow fluorescence indicates areas of cell death or production of ROS. Photographs were taken at $10 \mathrm{dpi}$. Scale bars, $50 \mu \mathrm{m}$.
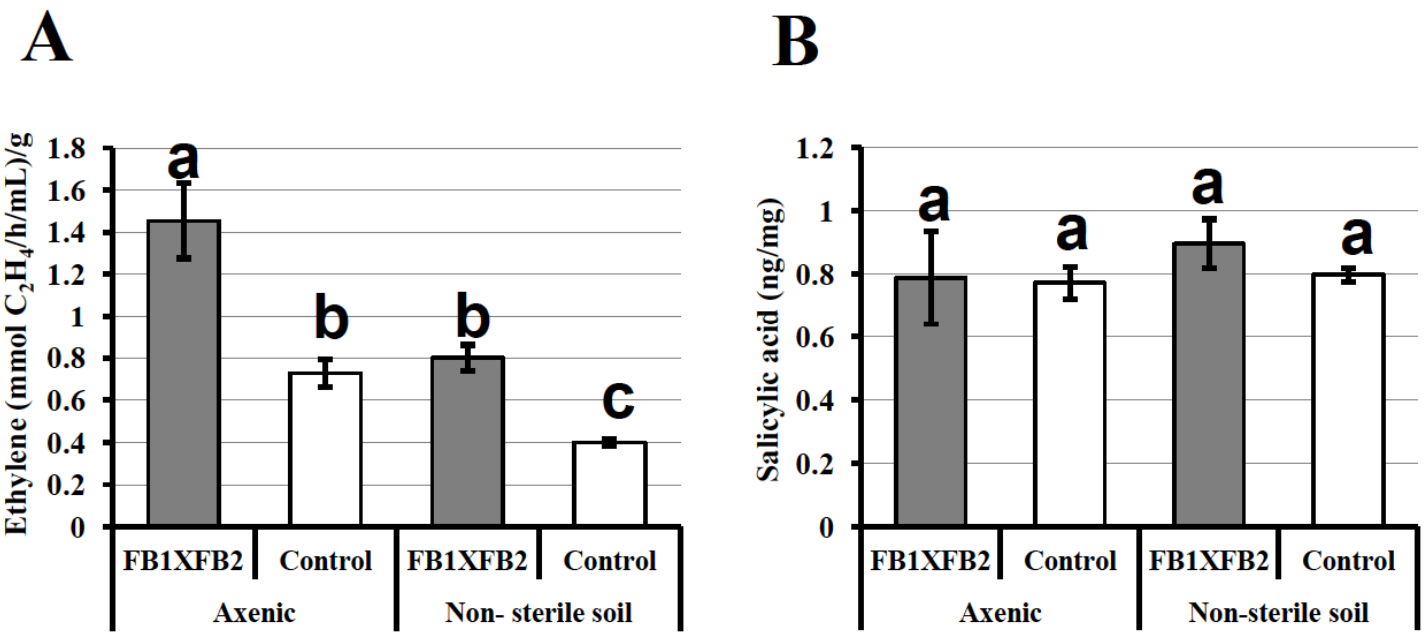

Figure 5: Production of phytohormones in maize plants infected by $U$. maydis observed at 10 dpi. A, determination of ethylene. B, determination of salicylic acid. Gray bars represent infected plants. White bars represent control plants that received SDW only. Data were obtained from three different experiments where three plants were used in each one. Lines on each bar represent standard error values, and different letters denote significant differences.

under axenic conditions, whereas the areas of tissue showing ROS production in plants inoculated in nonsterile soil were much smaller (see representative Figures 4A vs 4B). Also, it was noticeable that areas of plant tissue displaying cell death (Figures 4C vs 4D), and zones showing invasion of the fungus into the plants (see Figure 4C, inset), were observed mostly in the maize plants infected under axenic conditions. Control non-inoculated plants did not show ROS production or cell death (not shown). 


\section{Production of Phytohormones}

Infected plants, under either axenic or in non-sterile soil conditions, produced increased amounts of ethylene, compared to the control un-inoculated plants (Figure $\mathbf{5 A}$ ). On the other hand, roughly the same amounts of salicylic acid were produced by the infected and control plants (Figure 5B). In addition, it was observed that more ethylene was produced in the axenic plants compared to the plants inoculated in nonsterile soil (Figure 5A), but no significant difference was observed in the amounts of salicylic acids produced by plants grown under either conditions (Figure 5B).

\section{DISCUSSION}

Taking into consideration that no previous study on the priming effect has been made for the infection of maize with Ustilago maydis, the present study represents the first analysis that demonstrates that maize plants infected by $U$. maydis under axenic conditions, are more susceptible than those infected in non-sterile soil. Our data obtained suggest that indeed, the severity of maize disease caused by this fungus depended on the growth conditions of the plants, being more aggressive when plants are grown under axenic condition. This different behavior is probably due to the phenomenon of induced resistance or priming by which plants develop resistance against pathogens when previously exposed to both biotic and abiotic stresses $[6,9,29,30]$; in the present case exposure to the soil microbial population. Among the phenotypic differences observed in plants inoculated under either condition, axenic or in non-sterile soil, we may cite: inhibition of plant growth, the time elapsing for tumor and teliospores formation, size of tumors, cell death, ROS production, and phytohormone induction.

We suggest that cell death and ROS production observed in plant sections is not a hypersensitive reaction of the maize plant, but a symptom of the necrotic damage produced by the invasion of the pathogen. This suggestion is based on the observation that plants infected showed a higher level of these symptoms when inoculated under axenic conditions, compared to those infected in non sterile soil (exposed to both abiotic and abiotic stresses). Besides, it is important to recall that $U$. maydis is not a necrotrophic pathogen, but a biotrophic one $[13,14]$.

$U$. maydis has the ability to reprogram transcriptionally and metabolically its natural host during its infective process [3,31], and also the experimental alternative host Arabidopsis thaliana [17]. This capacity is due to transcription factors, several effector proteins, and virulence factors such as Cmu1 [14,17,32-34]. Cmu1 is a chorismate mutase secreted by the invasive $U$. maydis into the plant, causing changes in the shikimate pathway, and the synthesis of some amino acids. It also suppresses salicylic acid (SA) production $[32,35]$. Accordingly, in this work we did not observe that $U$. maydis infection induced an increase in SA production above the normal basal levels present in healthy plants. We have previously described that CMU1, effector genes, and genes encoding degradation enzymes are epigenetically regulated [36].

In this work we observed highly increased levels of ET production in the infected plants, especially those infected under axenic conditions. This observation is important since it has been described that different necrotrophic fungi induced in the plant high amounts of ET [37], and it may be recalled that $U$. maydis is a biotrophic fungus (see $[3,32]$; and revised by $[33,34]$ ). Accordingly it may be wondered if the fungus shows a "necrotrophic"-like behavior when infecting maize plants grown axenically, in contrast to its behavior with plants grown in soil.

\section{CONCLUSION}

In summary, in this work we have obtained one important novel observation: maize plants infected under axenic and sterile soil conditions are more susceptible to $U$. maydis infection than those plants infected under non-sterile soil conditions; probably because these, being in contact with microorganisms of the environment, have acquired the general mechanisms of resistance against pathogens known as induced resistance or priming. Also the observation that $U$. maydis behaves differently when infecting its natural host under sterile conditions, in contrast to the natural conditions in the field speaks about a change of biotrophic to necrotrophic-like behavior.

\section{ACKNOWLEDGEMENTS}

This work was partially supported by Consejo Nacional de Ciencia y Tecnología (CONACYT), México. Thanks are given to Drs. Jorge Molina-Torres, Juan J. Peña-Cabriales, and Alba E. Jofre-y-Garfias for providing some materials. Fernando Emilio PérezGarcía, Antonio Vera-Nuñez, Enrique RamírezChávez, and Rosario Razo-Belmán assisted in some analyses. All of them are members of the Departments 
of Biotechnology or Genetic Engineering of Centro de Investigación y de Estudios Avanzados del IPN, CINVESTAV Irapuato, México.

\section{REFERENCES}

[1] Ferreira RB, Monteiro S, Freitas R, Santos CS, Chen Z, Batista LM, Duarte J, Borges A, Teixeira AR. Fungal pathogens: the battle for plant infection. Crit Rev Plant Sci 2006; 25: 505-24.

http://dx.doi.org/10.1080/07352680601054610

[2] Ferreira RB, Monteiro S, Freitas R, Santos CN, Chen Z, Batista LM, Duarte J, Borges A, Teixeira AR. The role of plant defence proteins in fungal pathogenesis. Mol Plant Pathol 2007; 8: 677-700.

http://dx.doi.org/10.1111/j.1364-3703.2007.00419.x

[3] Doehlemann G, Wahl R, Horst RJ, Voll LM, Usadel B, Poree F, Stitt M, Pons-Kühnemann J, Sonnewald U, Kahmann R, Kämper J. Reprograming a maize plant: transcriptional and metabolic changes induced by fungal biotroph Ustilago maydis. Plant J 2008; 56: 181-95.

http://dx.doi.org/10.1111/j.1365-313X.2008.03590.x

[4] Zipfel C. Pattern-recognition receptors in plant innate immunity. Curr Opin Immunol 2008; 20: 10-6. http://dx.doi.org/10.1016/j.coi.2007.11.003

[5] Chester KS. The problem of acquired physiological immunity in plants. Q Rev Biol 1933; 8: 275-324.

http://dx.doi.org/10.1086/394440

[6] Conrath U. Priming of induced plant defense responses. In: Jean-Pierre J, Pierre G, Eds. Advances in botanical research. Amsterdam: Elsevier 2009; pp. 361-95.

[7] Heil M, Karban R. Explaining evolution of plant communication by airborne signals. Trends Ecol Evol 2010; 25: $137-44$.

http://dx.doi.org/10.1016/j.tree.2009.09.010

[8] Song Y, Chen D, Lu K, Sun Z, Zeng R. Enhanced tomato disease resistance primed by arbuscular mycorrhizal fungus. Front Plant Sci 2015; 6: 786.

http://dx.doi.org/10.3389/fpls.2015.00786

[9] Conrath U. Molecular aspects of defense priming. Trends Plant Sci 2011; 16: 524-31. http://dx.doi.org/10.1016/j.tplants.2011.06.004

[10] Planchamp C, Glauser G, Mauch-Mani B. Root inoculation with Pseudomonas putida KT2440 induces transcriptional and metabolic changes and systematic resistance in maize plants. Front Plant Sci 2015; 5: 719. http://dx.doi.org/10.3389/fpls.2014.00719

[11] Saville BJ, Donaldson ME, Doyle CE. Investigating Host Induced Meiosis in a Fungal Plant Pathogen. In: Swan A, editor. Meiosis-Molecular Mechanisms and Cytogenetic Diversity. Rijeka: Intech 2012; pp. 411-50.

[12] León-Ramírez CG, Sánchez-Arreguín JA, Ruiz-Herrera J. Ustilago maydis, a delicacy of the aztec cuisine and a model for research. Natural Resources 2014; 5: 256-67. http://dx.doi.org/10.4236/nr.2014.56024

[13] Bölker M. Ustilago maydis-a valuble model system for the study of fungal dimorphism and virulence. Microbiology 2001; 147: 1395-401. http://dx.doi.org/10.1099/00221287-147-6-1395

[14] Brefort T, Doehlemann G, Mendoza-Mendoza A, Reissmann $\mathrm{S}$, Djamei A, Kahmann R. Ustilago maydis as a patogen. Annu Rev Phytopathol 2009; 47: 423-45.

http://dx.doi.org/10.1146/annurev-phyto-080508-081923

[15] León-Ramírez CG, Cabrera-Ponce JL, Martínez-Espinoza $A D$, Herrera-Estrella L, Méndez L, Reynaga-Peña CG, RuizHerrera J. Infection of alternative host plant species by Ustilago maydis. New Phytol 2004; 164: 337-46. http://dx.doi.org/10.1111/j.1469-8137.2004.01171.x
[16] Méndez-Morán L, Reynaga-Peña CG, Springer PS, RuizHerrera J. Ustilago maydis infection of the non-natural host Arabidopsis thaliana. Phytopathology 2005; 95: 480-88. http://dx.doi.org/10.1094/PHYTO-95-0480

[17] Martínez-Soto D, Briones-Robledo AM, Estrada-Luna AA Ruiz-Herrera J. Transcriptomic analysis of Ustilago maydis infecting Arabidopsis reveals important aspects of the fungus pathogenic mechanisms. Plant Signal Behav 2013; 8: e25059 http://dx.doi.org/10.4161/psb.25059

[18] Mazaheri-Naeini M, Sabbagh SK, Martinez Y, SéjalonDelmas N, Roux C. Assessment of Ustilago maydis as a fungal model for root infection studies. Fugal Biol 2015; 119: 145-153. http://dx.doi.org/10.1016/i.funbio.2014.12.002

[19] Martínez-Soto D, Pérez-García FE, Ruiz-Herrera J. Arabidopsis infection by haploid or diploid strains of Ustilago maydis reveals its capacity as a necrotrophic or biotrophic phytopathogen. Fungal Genom Biol 2016; 6: 1. http://dx.doi.org/10.4172/2165-8056.1000133

[20] Banuett F, Herskowitz I. Different a alleles of Ustilago maydis are necessary for maintenance of filamentous growth but not for meiosis. Proc Natl Acad Sci USA 1989; 86: 5878-82. http://dx.doi.org/10.1073/pnas.86.15.5878

[21] Martínez-Espinoza AD, León-Ramírez CG, Elizarraraz G, Ruiz-Herrera J. Monomorphic nonpathogenic mutants of Ustilago maydis. Phytopathology 1997; 87: 259-65. http://dx.doi.org/10.1094/PHYTO.1997.87.3.259

[22] Ruiz-Herrera J, Martínez-Espinoza AD, Alvarez PE, Xoconostle-Cazares B. Carboxin-resistant mutant of Ustilago maydis is impaired in its pathogenicity for Zea mays. Curr Microbiol 1999; 39: 291-4. http://dx.doi.org/10.1007/s002849900461

[23] Holliday R. Ustilago maydis. In: King RC, editor. The Handbook of Genetics. New York: Plenum Press 1974; p. 575-95. http://dx.doi.org/10.1007/978-1-4899-1710-2 31

[24] Murashige T, Skoog F. A revised medium for growth and bioassays with tobacco tissue cultures. Physiol Plant 1962; 15: 473-97. http://dx.doi.org/10.1111/j.1399-3054.1962.tb08052.x

[25] Sato T, Oku H, Tsuruma K, Katsumura K, Shimazawa M, Hara $H$, Sugiyama $T$, Ikeda $T$. Effect of hypoxia on susceptibility of RGC-5 cells to nitric oxide. Invest Ophthalmol Vis Sci 2010; 51: 2575-86 http://dx.doi.org/10.1167/iovs.09-4303

[26] Martinez-Pacheco M, Ruiz-Herrera J. Diferential comparmentation of ornithine decarboxylase in cell of Mucor rouxii. J Gen Microbiol 1993; 139: 1387-94. http://dx.doi.org/10.1099/00221287-139-6-1387

[27] Altman SA, Randers L, Rau G. Comparison of trypan blue dye exclusion and fluorometric assay for mammalian cell viability determination. Biotechnol Prog 1993; 9: 671-74. http://dx.doi.org/10.1021/bp00024a017

[28] Malamy J, Hennig J, Klessig DF. Temperature-dependent induction of salicylic acid and its conjugates during the resistance response to tobacco mosaic virus infection. Plant Cell 1992; 4: 359-66. http://dx.doi.org/10.1105/tpc.4.3.359

[29] Conrath U, Pieterse CM, Mauch-Mani B. Priming in plantpathogen interactions. Trends Plant Sci 2002; 7: 210-16. http://dx.doi.org/10.1016/S1360-1385(02)02244-6

[30] Aranega-Bou P, de la O Leyva M, Finiti I, García-Agustín P, González-Bosch C. Priming of plant resistance by natural compounds. Hexanoic acid as a model. Front Plant Sci 2014. http://dx.doi.org/10.3389/fpls.2014.00488

[31] Morrison EN, Emery RJ, Saville BJ. Phytohormone involvement in the Ustilago maydis-Zea mays pathosystem: Relationships between abscisic acid and cytokin levels and 
strain virulence in infected cob tissue. PLoS One 2015; 10: e0130945.

http://dx.doi.org/10.1371/journal.pone.0130945

[32] Djamei A, Schipper K, Rabe F, Ghosh A, Vincon V, Kahnt J, Osorio S, Tohge T, Fernie AR, Feussner I, Feussner K, Meinicke P, Stierhof YD, Macek B, Mann M, Kahmann R. Metabolic priming by a secreted fungal effector. Nature 2011; 478: 395-98.

http://dx.doi.org/10.1038/nature10454

[33] Doehlemann G, Requena N, Schaefer $P$, Brunner $F$, O'Connell R, Parker JE. Reprogramming of plant cells by filamentous plant-colonizing microbes. New Phytol 2014; 204: 803-14.

http://dx.doi.org/10.1111/nph.12938

[34] Okmen B, Doehlemann G. Inside plant: biotrophic strategies to modulate host immunity and metabolism. Curr Opin Plant Biol 2014; 20: 19-25.

http://dx.doi.org/10.1016/j.pbi.2014.03.011
[35] Rabe F, Ajami-Rashidi Z, Doehlemann G, Kahmann R, Djamei A. Degradation of the plant defense hormone salicylic acid by the biotrophic fungus Ustilago maydis. Mol Microbiol 2013; 89: 179-88.

http://dx.doi.org/10.1111/mmi.12269

[36] Martínez-Soto D, González-Prieto JM, Ruiz-Herrera J. Transcriptomic analysis of the GCN5 gene reveals mechanisms of the epigenetic regulation of virulence and morphogenesis in Ustilago maydis. FEMS Yeast Res 2015. http://dx.doi.org/10.1093/femsyr/fov055

[37] Glazebrook J. Contrasting mechanisms of defense against biotrophic and necrotrophic pathogens. Annu Rev Phytopathol 2005; 43: 205-27.

http://dx.doi.org/10.1146/annurev.phyto.43.040204.135923

DOI: http://dx.doi.org/10.6000/1927-3037.2016.05.02.4

(C) 2016 Martínez-Soto and Ruiz-Herrera; Licensee Lifescience Global.

This is an open access article licensed under the terms of the Creative Commons Attribution Non-Commercial License (http://creativecommons.org/licenses/by-nc/3.0/) which permits unrestricted, non-commercial use, distribution and reproduction in any medium, provided the work is properly cited. 